\title{
Nanocrystalline Axially Bridged Iron Phthalocyanine Polymeric Conductor: $(\mu$-Thiocyanato)(phthalocyaninato)iron(III)
}

\author{
Eiza Shimizu, ${ }^{1}$ Gil Nonato Santos, ${ }^{2,3}$ and Derrick Ethelbhert Yu${ }^{1,3}$ \\ ${ }^{1}$ Department of Chemistry, College of Science, De La Salle University, 2401 Taft Avenue, Manila, Philippines \\ ${ }^{2}$ Department of Physics, College of Science, De La Salle University, 2401 Taft Avenue, Manila, Philippines \\ ${ }^{3}$ Materials Science and Nanotechnology Unit, De La Salle University, 2401 Taft Avenue, Manila, Philippines
}

Correspondence should be addressed to Derrick Ethelbhert Yu; derrick.yu@dlsu.edu.ph

Received 10 June 2016; Revised 12 August 2016; Accepted 21 August 2016

Academic Editor: Carlos R. Cabrera

Copyright (C) 2016 Eiza Shimizu et al. This is an open access article distributed under the Creative Commons Attribution License, which permits unrestricted use, distribution, and reproduction in any medium, provided the original work is properly cited.

\begin{abstract}
Skewered Iron(III) phthalocyanine conducting polymer can be constructed with the utilization of axial thiocyanato ligands $((\mu$ thiocyanato)(phthalocyaninato)iron(III)); $\left(\left[\mathrm{Fe}^{\mathrm{III}}(\mathrm{Pc})(\mathrm{SCN})\right]_{n}\right)$ thereby creating additional avenues for electron transport through a linear SCN bridge, apart from the intermolecular $\pi-\pi$ orbital overlap between the Pc molecules. In this paper, we report on the conversion of bulk $\left[\mathrm{Fe}{ }^{\mathrm{III}}(\mathrm{Pc})(\mathrm{SCN})\right]_{n}$ polymeric organic conductor into crystalline nanostructures through horizontal vapor phase growth process. The needle-like nanostructures are deemed to provide more ordered and, thus, more $\pi-\pi$ interactive interskewer $\left[\mathrm{Fe}^{\mathrm{III}}(\mathrm{Pc})(\mathrm{SCN})\right]_{n}$ polymer orientation, resulting in a twofold increase of its electrical conductivity per materials density unit.
\end{abstract}

\section{Introduction}

Phthalocyanines (Pc; Scheme 1) with metal centers (MPc) are considered to be one of the most promising organic conductors because of its flat and fully conjugated structure that provides facile intramolecular $\pi$-electron delocalization. Furthermore, the face-to-face stacking of MPcs paves the way for intermolecular $\pi$-electron overlap, leading to intermolecular electron transport [1].

The versatility of MPc as building blocks for molecular conductors can further be utilized through the attachment of axial ligands to its metal center (octahedral) which would result in either slip-stacked arrangement [2] or a "shishkebab" polymeric form [3-5]. The electrical conduction of slip-stacked MPc units highly depends on its arrangement in solid-state which is mainly due to the effectiveness of its intermolecular $\pi-\pi$ orbital overlap/interaction (Scheme 2(a)) $[6,7]$, while the polymerization of $\mathrm{MPcL}_{2}$ through axialligand (bidentate) bridge extends the highly delocalized $\pi$ electron of the macrocycle by forming linear $\pi$-electron containing organic molecules, resulting in additional stacking dimension for the $\pi$-electron transport, and thereby minimizing dependence on solid-state orientation (Scheme 2(b)) [8]. Furthermore, the introduction of a bridging ligand not only improves the geometry of the Pc's leading to an increase of electrical conductivity but also induces a doping effect and modulation of electron transport due to ligand field effect, wherein electron delocalization is inversely proportional to the axial/bridging ligand energy [9]. Thus, polymerization through the linear and relatively low-energy SCN axial/bridging ligands extends the molecule's $\pi$ system by creating linear conduction pathway through the Fe-SCNFe spine.

Nanosynthesis of bulk Pcs was shown to increase the electrical conductivity of molecules [10]. In a recent study, FePc was converted into nanostructure via the newly developed horizontal vapor phase growth (HVPG) technique [10, 11]. The nano-FePc was found to have twice the conductivity of the bulk FePc [10]. Nanosynthesis of FePc makes the adjacent Pcs more closely packed and have orderly solidstate arrangement, making the electrons freely move thereby creating efficient electronic transport systems $[12,13]$.

In this study, we explore on the possibility of further increasing the electrical conductivity of the $\left[\mathrm{Fe}^{\mathrm{III}}(\mathrm{Pc})(\mathrm{SCN})\right]_{n}$ polymeric system through its conversion into nanostructures. Bulk $\left[\mathrm{Fe}^{\mathrm{III}}(\mathrm{Pc})(\mathrm{SCN})\right]_{n}$ is synthesized by first oxidizing $\mathrm{Fe}^{2+}$ to $\mathrm{Fe}^{3+}$ to enable octahedral configuration thereby resulting 


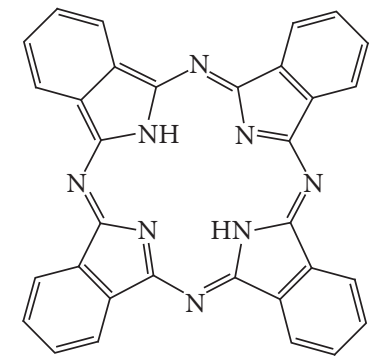

SCHEME 1: Structure of phthalocyanine (Pc).

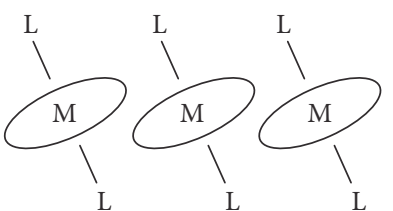

(a)

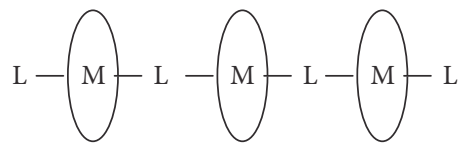

(b)

Scheme 2: (a) Slip-stacked and (b) skewered axially ligated MPc architectures.

in diaxial ligation. The oxidation is done with the reaction of $\mathrm{Fe}^{\mathrm{II}}(\mathrm{Pc})$ with $\mathrm{SOCl}_{2}$ to produce a highly oxidized $\mathrm{Fe}^{\mathrm{III}}(\mathrm{Pc}) \mathrm{Cl}_{2}$ radical. $\mathrm{Fe}^{\mathrm{III}}(\mathrm{Pc}) \mathrm{Cl}_{2}$ is reacted with $\mathrm{KSCN}$ to produce the soluble $\mathrm{K}\left[\mathrm{Fe}^{\mathrm{III}}(\mathrm{Pc})(\mathrm{SCN})_{2}\right]$ salt. Polymeric $\left[\mathrm{Fe}^{\mathrm{III}}(\mathrm{Pc})(\mathrm{SCN})\right]_{n}$ is synthesized by suspension of $\mathrm{K}\left[\mathrm{Fe}^{\mathrm{III}}(\mathrm{Pc})(\mathrm{SCN})_{2}\right]$ in water and heating the solution to $95^{\circ} \mathrm{C}$ to initiate polymerization. $\left[\mathrm{Fe}^{\mathrm{III}}(\mathrm{Pc})(\mathrm{SCN})\right]_{n}$ polymer is converted to nanoscale structures by horizontal vapor phase growth (HVPG) technique. Molecular characterizations are done by UV-Vis spectroscopy and FT-IR spectroscopy analyses, while the morphological images were characterized by Scanning Electron Microscope (SEM), elemental composition is analyzed by Energy Dispersive X-Ray (EDX), and the electrical conductivity is measured using van der Pauw (4-probe) method.

The resulting nanostructured $\left[\mathrm{Fe}^{\mathrm{III}}(\mathrm{Pc})(\mathrm{SCN})\right]_{n}$ provide multidimensional $\pi$-electron transport in the Pc molecule by adopting the enforced tetragonal packing that further increases the stacking dimensionality by producing intra- and inter- (skewer) $\pi$-orbital interactions (Scheme 3), thus, the higher electrical conductivity. This technique may serve as a facile and convenient method for increasing the conductivity of organic polymers with similar linear architectures, for which it may be considered as a promising class of molecular conductor.

\section{Methodology}

2.1. Synthesis of $\mathrm{Fe}(\mathrm{Pc}) \mathrm{Cl}_{2}$. The synthesis of dichloro(phthalocyaninato)iron(II) $\left[\mathrm{Fe}(\mathrm{Pc}) \mathrm{Cl}_{2}\right]$ was done through a previously reported procedure [14]. FePc (2.84 grams, $5 \mathrm{mmol}$ ) was suspended in $50 \mathrm{~mL}$ nitrobenzene. Then, $5.07 \mathrm{~mL}$ $(70.0 \mathrm{mmol})$ thionyl chloride, $\mathrm{SOCl}_{2}$, was subsequently added to the reaction vessel. The mixture was refluxed at $70^{\circ} \mathrm{C}$ in $\mathrm{N}_{2}$ atmosphere for 3 hours with constant stirring. Then, the mixture was cooled and filtered and the blue-black product was washed with ethanol and allowed to dry. The reaction yielded 2.493 grams of product (78\% yield).

2.2. Synthesis of $\mathrm{K}\left[\mathrm{Fe}^{\mathrm{III}} \mathrm{Pc}(\mathrm{SCN})_{2}\right]$. $\mathrm{K}\left[\mathrm{Fe}{ }^{\mathrm{III}}(\mathrm{Pc})(\mathrm{SCN})_{2}\right]$ was synthesized using a reported procedure [15]. $\mathrm{Fe}^{\mathrm{III}}\left(\mathrm{Pc}^{\mathrm{II}}\right) \mathrm{Cl}_{2}(1.92$ grams, $3.0 \mathrm{mmol}$ ) was added to 6.03 grams $(62 \mathrm{mmol})$ potassium thiocyanate, KSCN. Then, $100 \mathrm{~mL}$ acetone was added and the mixture was stirred for 72 hours at room temperature in $\mathrm{N}_{2}$ atmosphere. The thick suspension was vacuum filtered and was washed with cold distilled water and ethanol. The reaction yielded 1.39 grams of dark blue powder (64\% yield).

2.3. Synthesis of $\left[\mathrm{Fe}^{I I I}(\mathrm{Pc})(\mathrm{SCN})\right]_{n}$. $\left[\mathrm{Fe}^{\mathrm{III}}(\mathrm{Pc})(\mathrm{SCN})\right]_{n}$ was synthesized using a previously reported bridged MPc polymerization method $[15,16]$. K $\left[\mathrm{Fe}^{\mathrm{III}}(\mathrm{Pc})(\mathrm{SCN})_{2}\right](0.28$ grams, $0.3869 \mathrm{mmol}$ ) was suspended in $140 \mathrm{~mL}$ distilled water and was refluxed at $95^{\circ} \mathrm{C}$ with constant stirring for 14 days. This produced a green-black suspension and was filtered through gravity filtration. The reaction yielded 0.115 grams of black powder ( $47 \%$ yield).

2.4. Characterization. FePc, $\mathrm{K}\left[\mathrm{Fe}^{\mathrm{III}}(\mathrm{Pc})(\mathrm{SCN})_{2}\right]$, and $\left[\mathrm{Fe}^{\mathrm{III}}(\mathrm{Pc})(\mathrm{SCN})\right]_{n}$ were analyzed using (a) UV-Vis Spectrophotometer (Hitachi U-2900), (b) FT-IR Spectrophotometer (Nicolet Magna-IR 550), and (c) EDX (Oxford ISIS). For the UV-Vis analysis, 20 ppm FePc and $\mathrm{K}\left[\mathrm{Fe}^{\mathrm{III}}(\mathrm{Pc})(\mathrm{SCN})_{2}\right]$ were prepared by dissolving $10 \mathrm{mg}$ each of the sample in $50.0 \mathrm{~mL}$ DMF. The UV-Vis Spectrophotometer was set at wavelength scan $\left(\lambda=200\right.$ to $900 \mathrm{~nm}$ ), and their corresponding $\lambda_{\max }$ were recorded. For the IR profile of $\mathrm{K}\left[\mathrm{Fe}^{\mathrm{III}}(\mathrm{Pc})(\mathrm{SCN})_{2}\right]$ and $\left[\mathrm{Fe}^{\mathrm{III}}(\mathrm{Pc})(\mathrm{SCN})\right]_{n}$, pelletized sample was run from 400 to $4000 \mathrm{~cm}^{-1}$. For the EDX analysis, sample was coated with gold (20 mm for 30 seconds) and was placed inside the SEM sample holder. The EDX analysis is used in conjunction with 


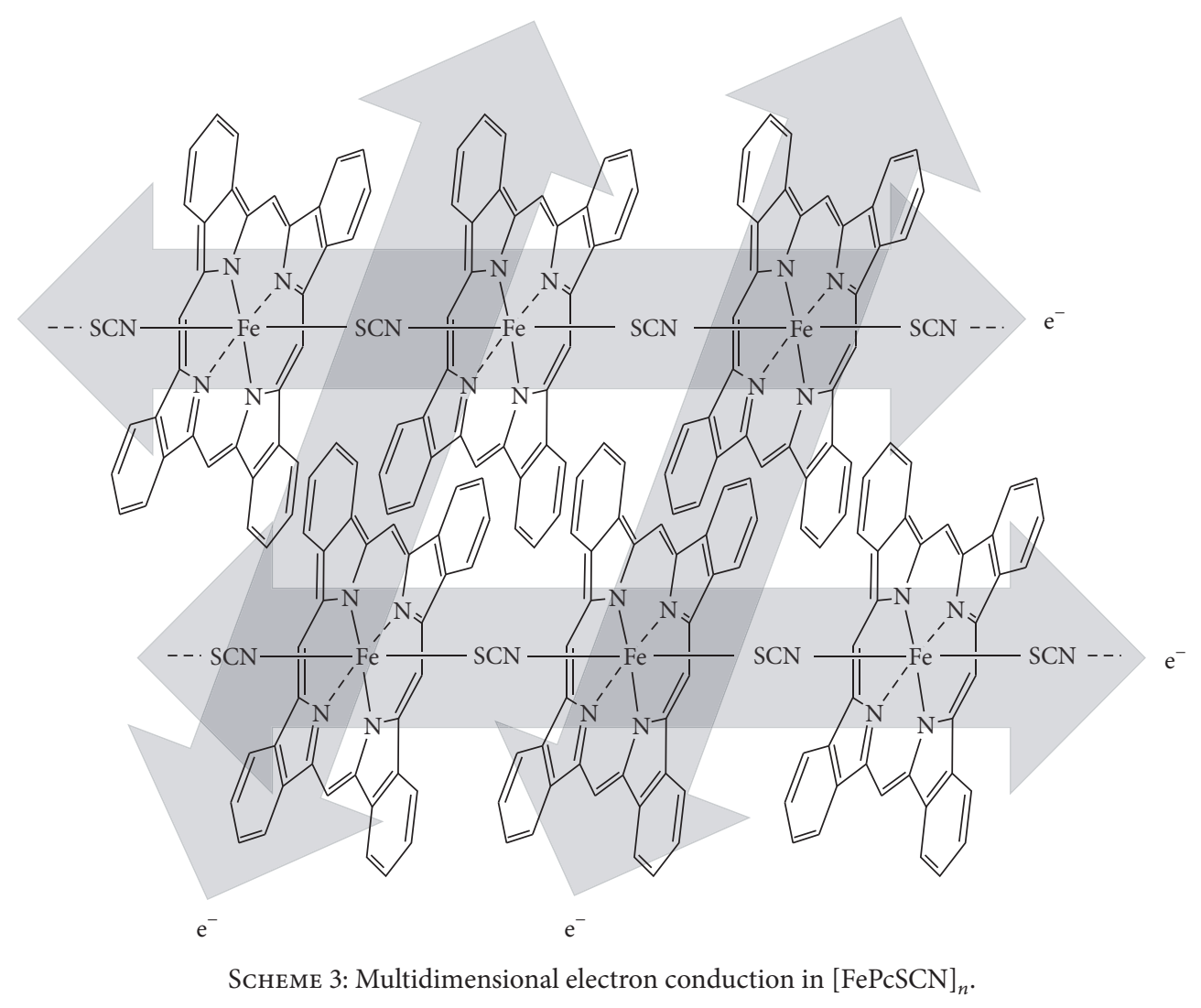

SEM. Thus, through the SEM (JEOL 5310), the surface of the sample was first viewed, and a flat, uniform smooth surface was chosen for the EDX analysis.

2.5. Nanostructure Synthesis. The HVPG technique employed 10-inch silica oven heating tubes and silicone $\mathrm{O}$ rings for the vacuum sealing and nanostructure synthesis. An oxygen-fuel torch was used to seal the tubes, while the Thermionics Vacuum System was used as vacuum. The baking was done in a conventional tube furnace [11] at $400^{\circ} \mathrm{C}$ for 4 hours. A representative visible deposit from the baked tubes was obtained and chemically characterized with UV and IR analyses by using the same sample preparation and instrumental conditions used in its bulk counterpart. Then, its morphology was analyzed using SEM and the elemental analysis by EDX. A representative piece of silica tube with visible deposit was obtained and placed in a gold stage plate and the same sample preparation and instrument conditions used by its bulk counterpart were also applied to the baked sample.

2.6. Electrical Resistivity. The set-up for the van der Pauw (4-probe) method [17] for the conductivity measurement includes Lodestar PS-303 DC power supply, switch board, Fluke 115 digital multimeter, and Keithley 224 programmable current source (range: $5 \mathrm{nA}-100 \mathrm{~mA}$ ).

The electrical resistance of $\mathrm{K}\left[\mathrm{Fe}^{\mathrm{III}}(\mathrm{Pc})(\mathrm{SCN})_{2}\right]$, $\left[\mathrm{Fe}^{\mathrm{III}}(\mathrm{Pc})(\mathrm{SCN})\right]_{n}$, and nano- $\left[\mathrm{Fe}^{\mathrm{III}}(\mathrm{Pc})(\mathrm{SCN})\right]_{n}$ were measured. The samples $(0.60 \mathrm{~g})$ were compressed into pellet using a hydraulic press $\left(10^{3} \mathrm{psi}\right)$ that produced approximately $5 \mathrm{~mm}$ diameter homogenous pellet sample. The pelletized sample was placed on a printed circuit board (PCB), which was connected to the switch board.

\section{Results and Discussion}

The Fe central metal in FePc has a 2+ oxidation state which results in a square planar configuration. However, an octahedral metal center is needed to accommodate diaxial ligands. Thus, the oxidation of Fe from 2+ (trigonal bipyramidal) to $3+$ was done by oxidative chlorination of FePc using $\mathrm{SOCl}_{2}$. $\mathrm{SOCl}_{2}$ forms $\mathrm{SCl}_{2}, \mathrm{SO}_{2}$, and $\mathrm{Cl}_{2}$ at room temperature and further increases its decomposition at elevated temperature under inert atmosphere. The synthesis was done under $\mathrm{N}_{2}$ gas atmosphere since $\mathrm{SOCl}_{2}$ reacts with water vapor forming $\mathrm{SO}_{2}$ and $\mathrm{HCl}$. The resulting dark blue solution was vacuum filtered and washed with ethanol to remove the solvent nitrobenzene. The dried product was blue-black powder.

$\mathrm{K}\left[\mathrm{Fe}^{\mathrm{III}}(\mathrm{Pc})(\mathrm{SCN})_{2}\right]$ was formed by the reaction of $\mathrm{Fe}^{\mathrm{III}}(\mathrm{Pc}) \mathrm{Cl}_{2}$ with $\mathrm{KSCN}$ through ligand substitution. $\mathrm{K}\left[\mathrm{Fe}^{\mathrm{III}}(\mathrm{Pc})(\mathrm{SCN})_{2}\right]$ may polymerize in water at elevated temperature; thus, it was washed with cold distilled water to inhibit polymerization. The product was dark blue powder. Purity of sample was confirmed by thin layer chromatography (TLC); solvent system used was $70: 30$ hexane : ethanol with $\mathrm{Rf}$ value of 0.40 . 


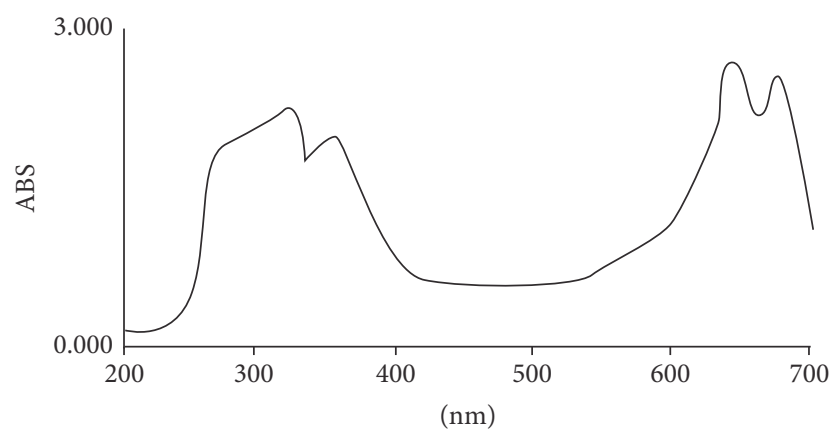

(a)

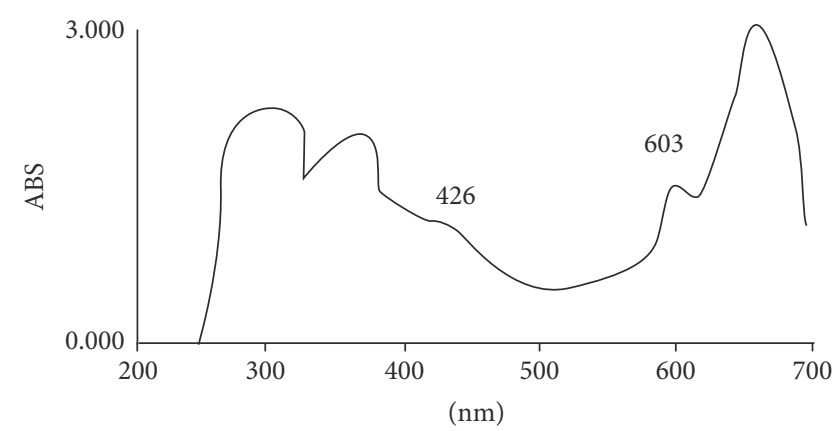

(b)

FIGURE 1: UV-Vis spectra of (a) FePc and (b) $\mathrm{K}\left[\mathrm{Fe}^{\mathrm{III}}(\mathrm{Pc})(\mathrm{SCN})_{2}\right]$.

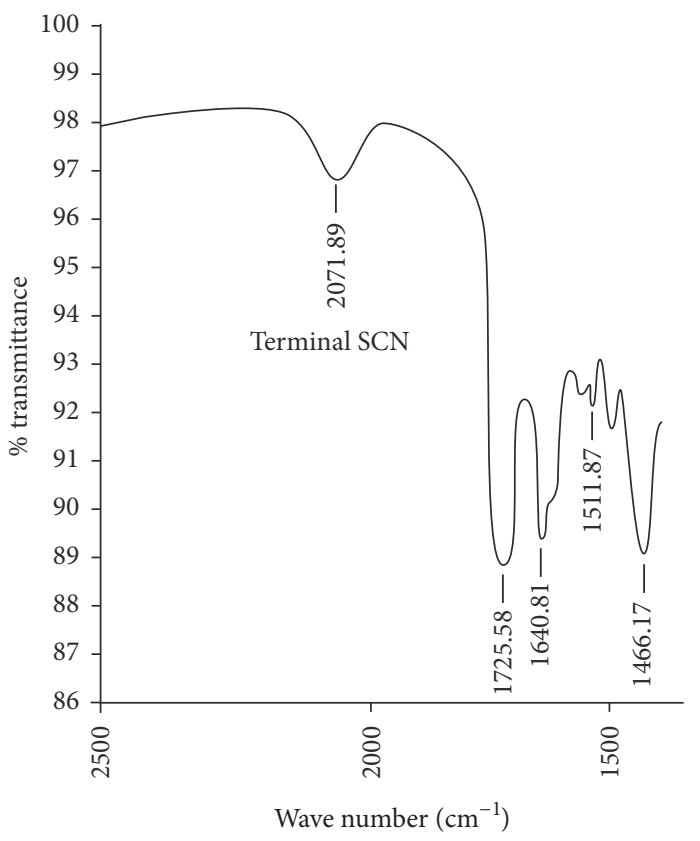

(a)

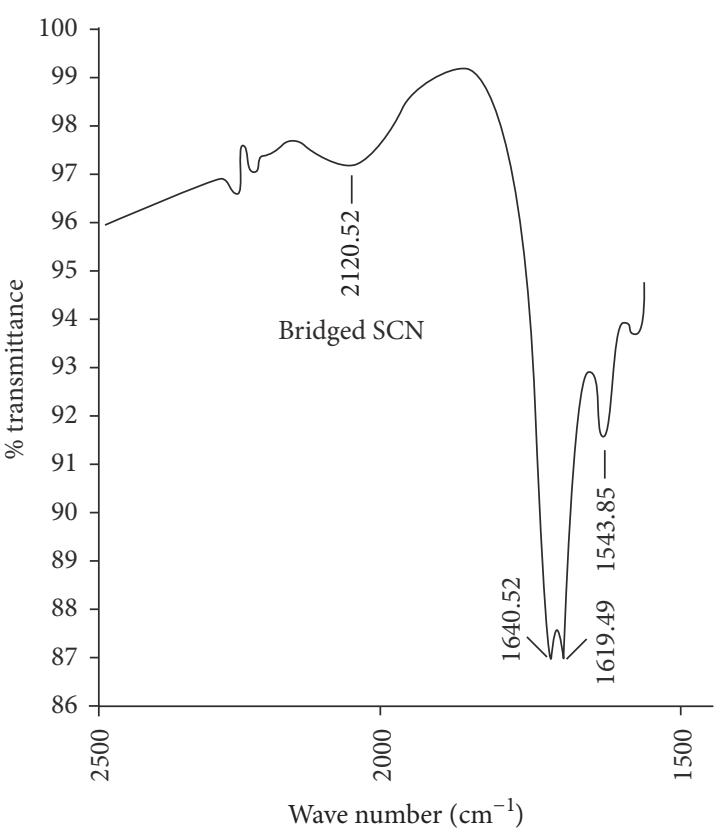

(b)

FIgURE 2: IR spectra of (a) $\mathrm{K}\left[\mathrm{Fe}^{\mathrm{III}}(\mathrm{Pc})(\mathrm{SCN})_{2}\right]$ and (b) $\left[\mathrm{Fe}^{\mathrm{III}}(\mathrm{Pc})(\mathrm{SCN})\right]_{n}$.

The formation of $\left[\mathrm{Fe}{ }^{\mathrm{III}}(\mathrm{Pc})(\mathrm{SCN})\right]_{n}$ involves the splitting off of the alkali metal thiocyanate from $\mathrm{K}\left[\mathrm{Fe}^{\mathrm{III}}(\mathrm{Pc})(\mathrm{SCN})_{2}\right]$ in water which was activated by heating the solution at $90-95^{\circ} \mathrm{C}$ $[3-5,8]$. The reaction was very slow, wherein the solution was constantly stirred for 14 days. The resulting solution was filtered and was washed with distilled water to eliminate the by-product $\mathrm{KSCN}$, leaving the black $\left[\mathrm{Fe}^{\mathrm{III}}(\mathrm{Pc})(\mathrm{SCN})\right]_{n}$. TLC was done to check the purity of the sample; solvent system used was $70: 30$ hexane : ethanol, with Rf value of 0.30 .

MPc complexes are absorbed at two main wavelengths: 300-350 nm (Soret Band) and 600-700 nm (Q-Band). $\mathrm{K}\left[\mathrm{Fe}^{\mathrm{III}}(\mathrm{Pc})(\mathrm{SCN})_{2}\right]$ was analyzed using $\mathrm{UV}-\mathrm{Vis}$ spectroscopy and was compared to the planar FePc, as shown in Figure 1(a). UV-Vis analysis was done to ensure the integrity of the phthalocyanine ring. The results confirm the presence of an intact Pc ring as shown by intense bands at 300-400 and $600-700 \mathrm{~nm}$, which were attributed to the $n-\pi^{*}$ and $\pi-\pi^{*}$ transitions, respectively. Further, $\mathrm{K}\left[\mathrm{Fe}^{\mathrm{III}}(\mathrm{Pc})(\mathrm{SCN})_{2}\right]$ show a shoulder peak characteristic to ligated MPcs at around 430 and $600 \mathrm{~nm}$, which is due to the metal-ligand charge transfer band that confirms the attachment of axial ligands to the complex (Figure 1(b)) [8].

Figures 2(a) and 2(b) display the IR profiles of $\mathrm{K}\left[\mathrm{Fe}^{\mathrm{III}}(\mathrm{Pc})(\mathrm{SCN})_{2}\right]$ and $\left[\mathrm{Fe}^{\mathrm{III}}(\mathrm{Pc})(\mathrm{SCN})\right]_{n}$ wherein the bands from $1500-1700 \mathrm{~cm}^{-1}$ correspond to the aromatic $\mathrm{C}=\mathrm{C}$ stretch of the Pc unit. More importantly, the bonding type of axial thiocyanate ligands has been established in the 2000$2200 \mathrm{~cm}^{-1}$ region, wherein it is generally observed that a broad and strong signal signifies metal-N-bonded compound while a weak and sharp peak shows metal-S-bonded compound [18]. The $2071 \mathrm{~cm}^{-1}$ peak (weak and sharp) of $\mathrm{K}\left[\mathrm{Fe}{ }^{\mathrm{III}}(\mathrm{Pc})(\mathrm{SCN})_{2}\right]$ signifies an S-bonded thiocyanate ligand to the Fe metal center. On the other hand, the $2120 \mathrm{~cm}^{-1}$ peak (weak and broad) is in between the general description for 


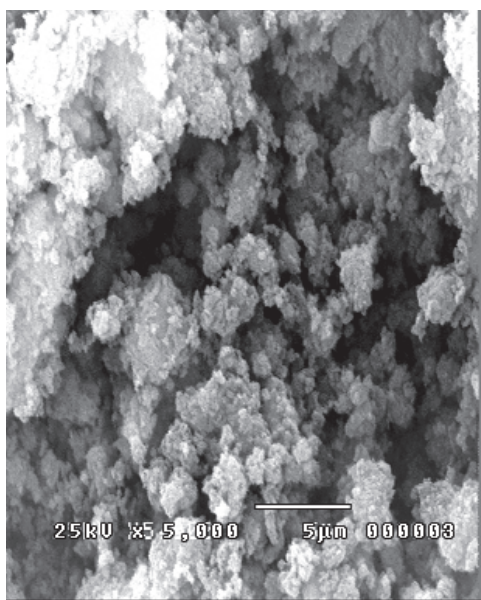

(a)

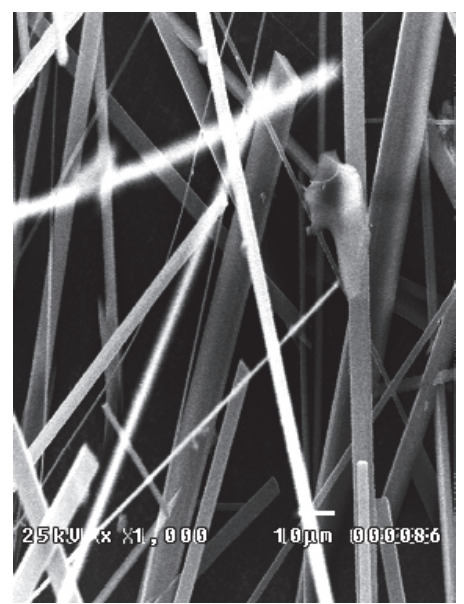

(b)

FIgURE 3: SEM images of (a) bulk FePc (powder) and (b) nano-FePc (crystalline).

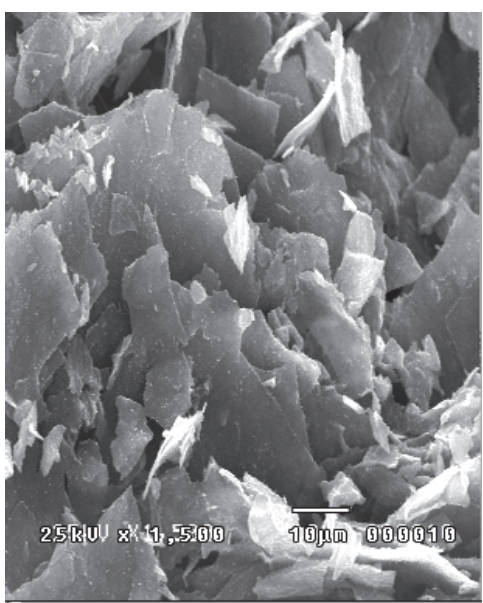

(a)

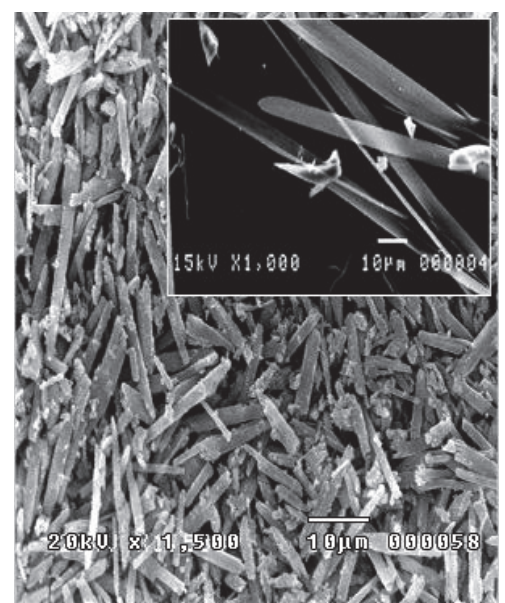

(b)

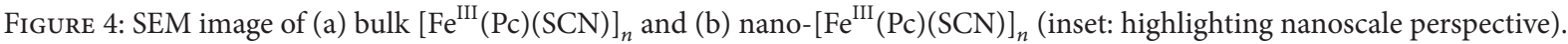

S-bonded and N-bonded thiocyanate ligand, signifying that the $\mathrm{CN}$ valence frequency is a bridging thiocyanate, as it has been reported that the $\mathrm{CN}$ valence frequency increases from free thiocyanate to metal-N, metal-S, and bridged species [18-20]. Thus, the $\mathrm{CN}$ valence frequency shift from $2071 \mathrm{~cm}^{-1}$ to $2120 \mathrm{~cm}^{-1}$ indicates the conversion of the free SCN ligand in $\mathrm{K}\left[\mathrm{Fe}^{\mathrm{III}}(\mathrm{Pc})(\mathrm{SCN})_{2}\right]$ to polymeric SCN-bridged $\left[\mathrm{Fe}^{\mathrm{III}}(\mathrm{Pc})(\mathrm{SCN})\right]_{n}$ species.

EDX elemental analyses of $\mathrm{FePc}, \mathrm{K}\left[\mathrm{Fe}^{\mathrm{III}}(\mathrm{Pc})(\mathrm{SCN})_{2}\right]$, and $\left[\mathrm{Fe}^{\mathrm{III}}(\mathrm{Pc})(\mathrm{SCN})\right]_{n}$ revealed elemental presence of iron, carbon, and nitrogen from the FePc unit, as well as sulfur which is derived from the axial SCN ligand.

Figure 3 shows the SEM images of (a) powder and (b) baked FePc. Bulk powder FePc appears to be a rocky dense solid with rough texture. On the other hand, baked FePc formed needle-like nanocrystalline structures thus confirming the morphological conversion of FePc by HVPG technique in an evacuated tube at $400^{\circ} \mathrm{C}$.
Different conditions had been employed for FePc nanosynthesis, resulting in nanostructured $\mathrm{FePc}$ with different morphologies. This was done for the method optimization for the $\left[\mathrm{Fe}^{\mathrm{III}}(\mathrm{Pc})(\mathrm{SCN})\right]_{n}$ nanosynthesis. Based on the FePc nanosynthesis optimization, it was found that a baking temperature of $400^{\circ} \mathrm{C}$ is optimal to convert the FePc from bulk to nanostructure. Due to this, $\left[\mathrm{Fe}^{\mathrm{III}}(\mathrm{Pc})(\mathrm{SCN})\right]_{n}$ was chosen to be baked at $400^{\circ} \mathrm{C}$ for 4 hours. SEM analysis revealed $\left[\mathrm{Fe}^{\mathrm{III}}(\mathrm{Pc})(\mathrm{SCN})\right]_{n}$ nanorods that is approximately $2 \mu \mathrm{m}$ wide and $10 \mu \mathrm{m}$ long (Figure 4(a)). The bulk polymer $\left[\mathrm{Fe}^{\mathrm{III}}(\mathrm{Pc})(\mathrm{SCN})\right]_{n}$ appeared as "thin sheets," confirming the morphological conversion into nanocrystalline structures by baking the sample at $400^{\circ} \mathrm{C}$ (Figure 4(b)).

As shown in Figure 5, the UV analysis of nanostructured $\left[\mathrm{Fe}^{\mathrm{III}}(\mathrm{Pc})(\mathrm{SCN})\right]_{n}$ shows absorption at 350 and $650 \mathrm{~nm}$ corresponding to Soret and Q-bands, respectively, which are the characteristic Pc ring absorption wavelengths, including the presence of the shoulder peak at around $600 \mathrm{~nm}$ which is 


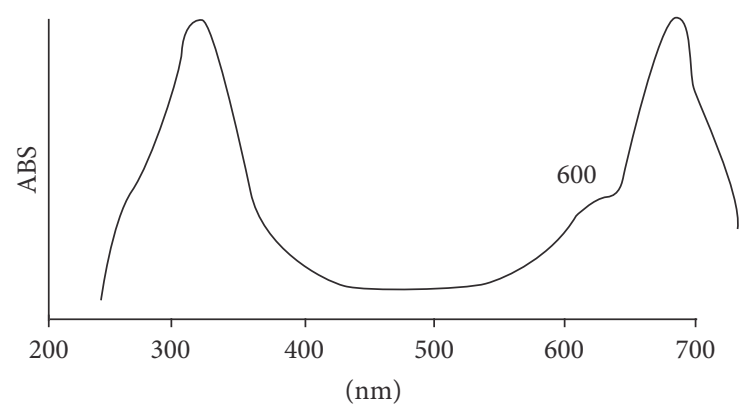

FIgURE 5: UV-Vis spectra of nano- $\left[\mathrm{Fe}^{\mathrm{III}}(\mathrm{Pc})(\mathrm{SCN})\right]_{n}$.

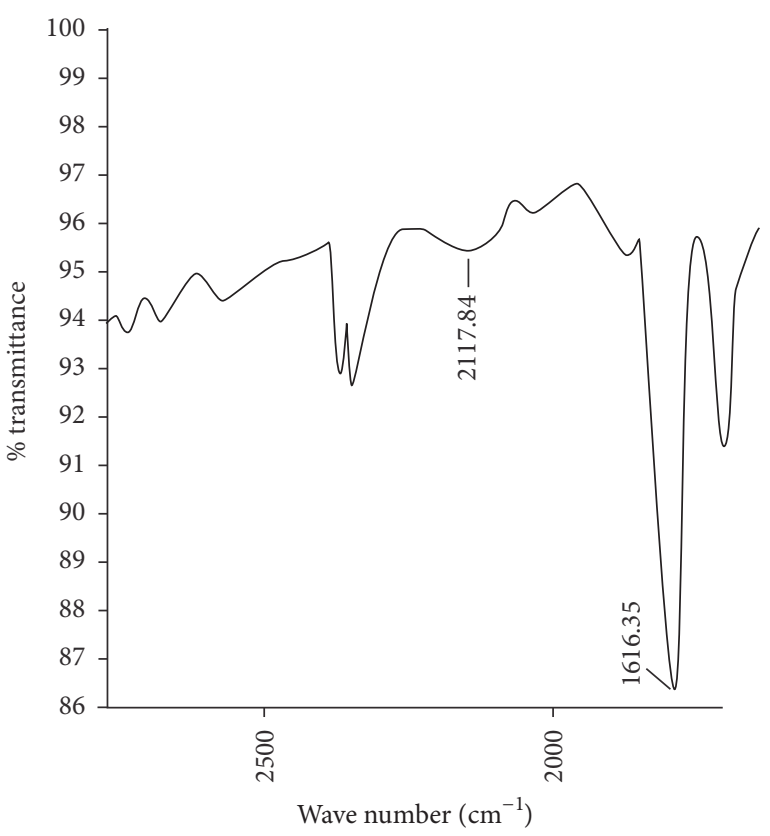

Figure 6: IR spectra of nano- $\left[\mathrm{Fe}^{\mathrm{III}}(\mathrm{Pc})(\mathrm{SCN})\right]_{n}$.

attributed to axially ligated metal center, thus, indicating an intact SCN-bridged MPc. This indicates that despite exposing the polymer at elevated temperature, no degradation of the $\left[\mathrm{Fe}^{\mathrm{III}}(\mathrm{Pc})(\mathrm{SCN})\right]_{n}$ occurred.

The IR analysis (Figure 6) of nanostructured $\left[\mathrm{Fe}^{\mathrm{III}}(\mathrm{Pc})(\mathrm{SCN})\right]_{n}$ revealed a broad and weak $\mathrm{CN}$ valence frequency at $2117 \mathrm{~cm}^{-1}$, which is similar to its bulk counterpart, thus further confirming an intact SCN-bridged FePc.

The nanostructured $\left[\mathrm{Fe}^{\mathrm{III}}(\mathrm{Pc})(\mathrm{SCN})\right]_{n}$ was also subjected to EDX analysis (Table 1), which revealed the elemental presence of $\mathrm{C}, \mathrm{N}, \mathrm{Fe}$, and $\mathrm{S}$ which further validate the attachment of SCN as bridging ligand to the polymeric complex.

The electrical conductivity of $\mathrm{K}\left[\mathrm{Fe}^{\mathrm{III}}(\mathrm{Pc})(\mathrm{SCN})_{2}\right]$, $\left[\mathrm{Fe}^{\mathrm{III}}(\mathrm{Pc})(\mathrm{SCN})\right]_{n}$, and nano- $\left[\mathrm{Fe} \mathrm{III}^{\mathrm{II}}(\mathrm{Pc})(\mathrm{SCN})\right]_{n}$ was determined using the 4-probe van der Pauw method. The sample was mounted in a printed circuit board (PCB) with four thin Ag wires symmetrically attached to the four points of the sample. The PCB wires were attached to its corresponding slot in the switch board. The switch board served as a control
TABle 1: EDX analysis of $\mathrm{FePc}, \quad \mathrm{K}\left[\mathrm{Fe}^{\mathrm{III}}(\mathrm{Pc})(\mathrm{SCN})_{2}\right]$, $\left[\mathrm{Fe}^{\mathrm{III}}(\mathrm{Pc})(\mathrm{SCN})\right]_{n}$, and nano- $\left[\mathrm{Fe}^{\mathrm{III}}(\mathrm{Pc})(\mathrm{SCN})\right]_{n}$.

\begin{tabular}{lc}
\hline Compound & Elements present \\
\hline $\mathrm{Fe}^{\mathrm{II}} \mathrm{Pc}$ & $\mathrm{C}, \mathrm{N}, \mathrm{Fe}$ \\
$\mathrm{Fe}^{\mathrm{III}}(\mathrm{Pc})(\mathrm{SCN})_{2}$ & $\mathrm{C}, \mathrm{N}, \mathrm{Fe}, \mathrm{S}$ \\
{$\left[\mathrm{Fe}^{\mathrm{III}}(\mathrm{Pc})(\mathrm{SCN})\right]_{n}$} & $\mathrm{C}, \mathrm{N}, \mathrm{Fe}, \mathrm{S}$ \\
$\mathrm{Nano}_{n}\left[\mathrm{Fe}{ }^{\mathrm{III}}(\mathrm{Pc})(\mathrm{SCN})\right]_{n}$ & $\mathrm{C}, \mathrm{N}, \mathrm{Fe}, \mathrm{S}$ \\
\hline
\end{tabular}

TABLE 2: Calculated conductivity of $\mathrm{K}\left[\mathrm{Fe}^{\mathrm{IIII}}(\mathrm{Pc})(\mathrm{SCN})_{2}\right]$, $\left[\mathrm{Fe}^{\mathrm{III}}(\mathrm{Pc})(\mathrm{SCN})\right]_{n}$, and Nano- $\left[\mathrm{Fe}^{\mathrm{III}}(\mathrm{Pc})(\mathrm{SCN})\right]_{n}$ (pelletized, $\left.10^{3} \mathrm{psi}\right)$.

\begin{tabular}{lc}
\hline Compound & Conductivity, S.cm \\
\hline $\mathrm{K}\left[\mathrm{Fe}^{\mathrm{III}}(\mathrm{Pc})(\mathrm{SCN})_{2}\right]$ & $2.95 \times 10^{-4}$ \\
{$\left[\mathrm{Fe}^{\mathrm{III}}(\mathrm{Pc})(\mathrm{SCN})\right]_{n}$} & $1.78 \times 10^{-3}$ \\
$\mathrm{Nano}^{-}\left[\mathrm{Fe}^{\mathrm{III}}(\mathrm{Pc})(\mathrm{SCN})\right]_{n}$ & $3.50 \times 10^{-3}$ \\
\hline
\end{tabular}

as to which points the current and its corresponding voltage reading will pass through. Current $\left(5.0 \times 10^{-4} \mathrm{~mA}\right)$ was allowed to pass through on one side of the sample and its corresponding voltage on the opposite side was recorded.

Table 2 indicates the conductivity of $\mathrm{K}\left[\mathrm{Fe}^{\mathrm{III}}(\mathrm{Pc})(\mathrm{SCN})_{2}\right]$, $\left[\mathrm{Fe}^{\mathrm{III}}(\mathrm{Pc})(\mathrm{SCN})\right]_{n}$ and nano- $\left[\mathrm{Fe}^{\mathrm{III}}(\mathrm{Pc})(\mathrm{SCN})\right]_{n}$ at room temperature. The conductivity increased by 1 order from SCN axially ligated $\mathrm{FePc}\left(2.95 \times 10^{-4} \mathrm{~S} \cdot \mathrm{cm}^{-1}\right)$ to SCN-skewered FePc $\left(1.78 \times 10^{-3} \mathrm{~S} \cdot \mathrm{cm}^{-1}\right)$ which is mainly attributed to the extended $\pi$-system conducting pathway in the polymer through the Fe-SCN-Fe spine. Also, the conductivity increased twice from the bulk $\left[\mathrm{Fe}^{\mathrm{III}}(\mathrm{Pc})(\mathrm{SCN})\right]_{n}$ to the nanostructured $\left[\mathrm{Fe}^{\mathrm{III}}(\mathrm{Pc})(\mathrm{SCN})\right]_{n}\left(3.50 \times 10^{-3} \mathrm{~S} \cdot \mathrm{cm}^{-1}\right)$. This is mainly because of the more orderly solid-state arrangement of the nanostructured polymer, resulting in a better and more efficient multidimensional electron transport.

The sample thickness was calculated using a viewing scope that was connected to the computer from which a screen caliper was used to measure the thickness of the sample. The radius of the pellet was measured using a conventional vernier caliper and the corresponding calculations were done for the determination of the sample density. As shown in Table 3, the density was calculated to be around $0.40-0.41 \mathrm{~g} / \mathrm{cm}^{3}$ for the two samples. The data can also be interpreted that only half the amount of nanostructured $\left[\mathrm{Fe}^{\mathrm{III}}(\mathrm{Pc})(\mathrm{SCN})\right]_{n}$ material is required to achieve the same electrical conductivity of bulk $\left[\mathrm{Fe}{ }^{\mathrm{III}}(\mathrm{Pc})(\mathrm{SCN})\right]_{n}$ which is an important attribute for miniaturization and optimization of electronic devices.

\section{Conclusion}

The transport of electrons in bridged MPcs can be further enhanced with the conversion of its bulk form into nanocrystalline structures. The skewered phthalocyanine conducting polymer $\left[\mathrm{Fe}^{\mathrm{III}}(\mathrm{Pc})(\mathrm{SCN})\right]_{n}$ can be converted into crystalline nanostructures via horizontal vapor phase 
TABLE 3: Density of measured samples for conductivity.

\begin{tabular}{|c|c|c|c|c|c|}
\hline Sample & Mass, $m(\mathrm{~g})$ & Radius, $r(\mathrm{~cm})$ & Thickness, $h(\mathrm{~cm})$ & Volume, $V=\pi r^{2} h\left(\mathrm{~cm}^{3}\right)$ & $\begin{array}{c}\text { Density } \\
m / V \\
\left(\mathrm{~g} / \mathrm{cm}^{3}\right)\end{array}$ \\
\hline Bulk $\left[\mathrm{Fe}^{\mathrm{III}}(\mathrm{Pc})(\mathrm{SCN})\right]_{n}$ & 0.0069 & 0.265 & 0.074 & 0.01633 & 0.42 \\
\hline Nano- $\left[\mathrm{Fe}^{\mathrm{III}}(\mathrm{Pc})(\mathrm{SCN})\right]_{n}$ & 0.0061 & 0.255 & 0.072 & 0.01471 & 0.41 \\
\hline
\end{tabular}

growth, thereby creating more order on the orientation of the skewered/"shish-kebab" polymeric chain. The process has resulted in a twofold increase in electrical conductivity of $[\mathrm{FePcSCN}]_{n}$ per unit density. Thus, the nanosynthesis of $\left[\mathrm{Fe}^{\mathrm{III}}(\mathrm{Pc})(\mathrm{SCN})\right]_{n}$ polymeric system provides a more efficient, multidimensional $\pi$-electron transport system which can be a promising class of organic conductors.

\section{Competing Interests}

The authors declare that they have no competing interests.

\section{References}

[1] T. J. Marks, "Interfaces between molecular and polymeric 'metals': electrically conductive, structure-enforced assemblies of metallomacrocycles," Angewandte Chemie-International Edition, vol. 29, pp. 857-879, 1990.

[2] T. Inabe and H. Tajima, "Phthalocyanines-versatile components of molecular conductors," Chemical Review, vol. 104, no. 11, pp. 5503-5534, 2004.

[3] J. Metz and M. Hanack, "Synthesis, characterization, and conductivity of ( $\mu$-cyano)(phthalocyaninato)cobalt(III)," Journal of the American Chemical Society, vol. 105, no. 4, pp. 828-830, 1983.

[4] L. R. Subramanian, "Tribute to Professor Dr Michael Hanack," Journal of Porphyrins and Phthalocyanines, vol. 4, no. 3, pp. 300309, 2000.

[5] N. B. McKeown, "Phthalocyanine-containing polymers," Journal of Materials Chemistry, vol. 10, no. 9, pp. 1979-1995, 2000.

[6] D. E. C. Yu, H. Imai, M. Ushio, S. Takeda, T. Naito, and T. Inabe, "One-step synthesis of partially oxidized cobalt(III) phthalocyanine salts with axial ligands," Chemistry Letters, vol. 35, no. 6, pp. 602-603, 2006.

[7] D. Yu, M. Matsuda, H. Tajima, T. Naito, and T. Inabe, "Stable $\pi-\pi$ dependent electron conduction band of TPP $\left[\mathrm{M}(\mathrm{Pc}) \mathrm{L}_{2}\right]_{2}$ molecular conductors $(\mathrm{TPP}=$ tetraphenylphosphonium; $\mathrm{M}=$ Co, Fe; Pc = phthalocyaninato; $\mathrm{L}=\mathrm{CN}, \mathrm{Cl}, \mathrm{Br})$," Dalton Transactions, vol. 40, no. 10, pp. 2283-2288, 2011.

[8] D. Yu, E. Gacho, G. Janairo, P. Ang, and S. Tan, "Skewered cyano-ligated cobalt 1,2-naphthalocyanine polymer: an electron transport engineering," The Manila Journal of Science, vol. 6, pp. 33-35, 2010.

[9] D. E. C. Yu, M. Matsuda, H. Tajima et al., "Variable magnetotransport properties in the $\operatorname{TPP}\left[\mathrm{Fe}(\mathrm{Pc}) \mathrm{L}_{2}\right]_{2}$ system $(\mathrm{TPP}=$ tetraphenylphosphonium, $\mathrm{Pc}=$ phthalocyaninato, $\mathrm{L}=\mathrm{CN}, \mathrm{Cl}$, and Br)," Journal of Materials Chemistry, vol. 19, no. 6, pp. 718723, 2009.

[10] P. Ang and S. Tan, Nano-based materials engineering of phthalocyanine molecular conductors [B.Sc. thesis], De La Salle University, Manila, Philippines, 2009.
[11] G. Santos, A. Salvador, and R. Quiroga, "Temperature and deposition time dependence of the geometrical properties of tin oxide nanostructures," International Journal of Scientific \& Engineering Research, vol. 2, pp. 1-6, 2011.

[12] X. Lu, W. Zhang, C. Wang, T.-C. Wen, and Y. Wei, "Onedimensional conducting polymer nanocomposites: synthesis, properties and applications," Progress in Polymer Science, vol. 36, no. 5, pp. 671-712, 2011.

[13] S.-J. Kim, M. Matsumoto, and K. Shigehara, "Synthesis and electrical properties of $\operatorname{poly}(\mu$-1,4-diisocyanobenzene) octacyanophthalocyaninatoiron(II)," Synthetic Metals, vol. 107, no. 1, pp. 27-33, 1999.

[14] J. F. Myers, G. W. Rayner Canham, and A. B. P. Lever, "Higher oxidation level phthalocyanine complexes of chromium, iron, cobalt, and zinc. Phthalocyanine radical species," Inorganic Chemistry, vol. 14, no. 3, pp. 461-468, 1975.

[15] M. Hanack, C. Hedtmann-Rein, A. Datz, U. Keppeler, and U. Munz, "Synthesis and Characterization of ( $\mu$-thiocyanato) and ( $\mu$-azido) phthalocyaninato metal complexes," Synthetic Metals, vol. 19, no. 1-3, pp. 787-792, 1987.

[16] C. Hedtmann-Rein, M. Hanack, K. Peters, E. M. Peters, and H. G. von Schnering, "Synthesis and properties of (phthalocyaninato)- and (tetrabenzoporphyrinato)cobalt(III) thiocyanate and isothiocyanate compounds. Crystal and molecular structure of (phthalocyaninato)(pyridine)(thiocyanato)cobalt(III)," Inorganic Chemistry, vol. 26, no. 16, pp. 2647-2651, 1987.

[17] L. van der Pauw, "A method of measuring specific resistivity and hall effect of discs of arbitrary shape," Philips Research Reports, vol. 13, pp. 1-9, 1958.

[18] R. A. Bailey, S. L. Kozak, T. W. Michelsen, and W. N. Mills, "Infrared spectra of complexes of the thiocyanate and related ions," Coordination Chemistry Reviews, vol. 6, no. 4, pp. 407$445,1971$.

[19] A. H. Norbury, "Coordination chemistry of the cyanate, thiocyanate, and selenocyanate ions," Advances in Inorganic Chemistry and Radiochemistry, vol. 17, pp. 231-386, 1975.

[20] A. Tomkiewicz, J. Klak, J. Mrozinski, J. Kłak, and J. Mroziński, "Bimetallic complexes with macrocyclic ligands.Variation of magnetic exchange interactions in some heteronuclear thiocyanatobridged compounds," Materials Science-Poland, vol. 22, pp. 253-263, 2004. 

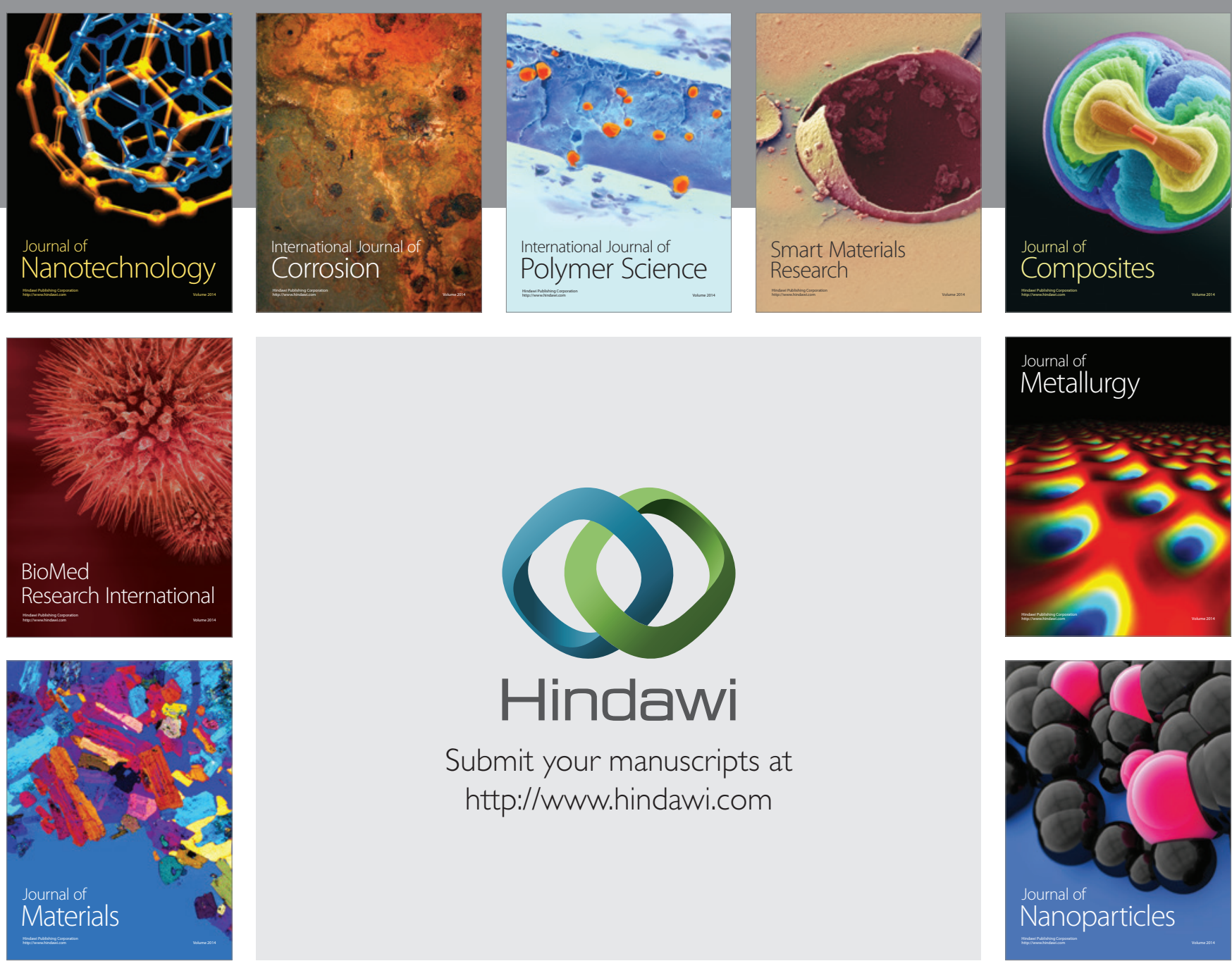

\section{Hindawi}

Submit your manuscripts at

http://www.hindawi.com

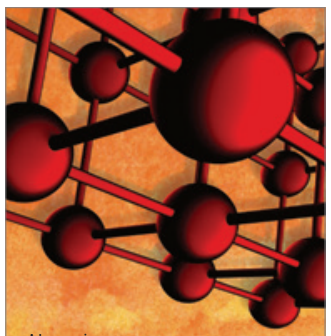

Materials Science and Engineering
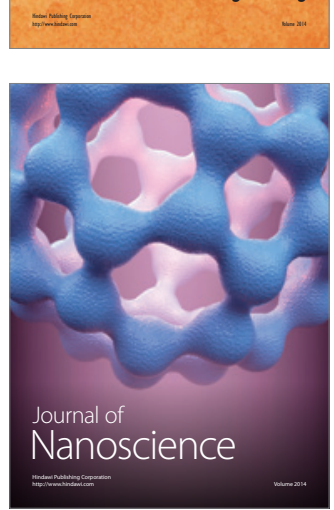
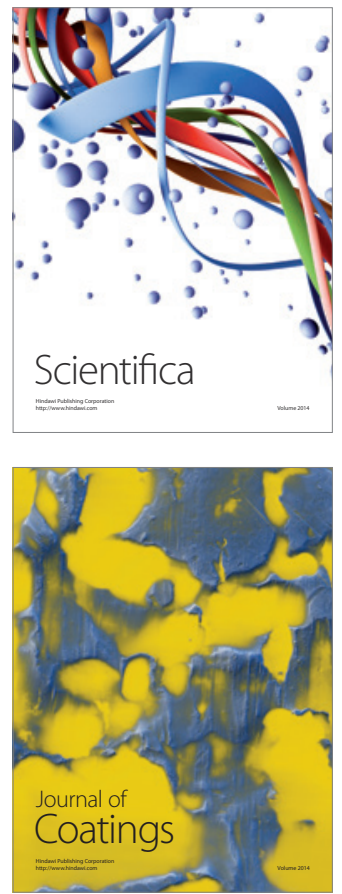
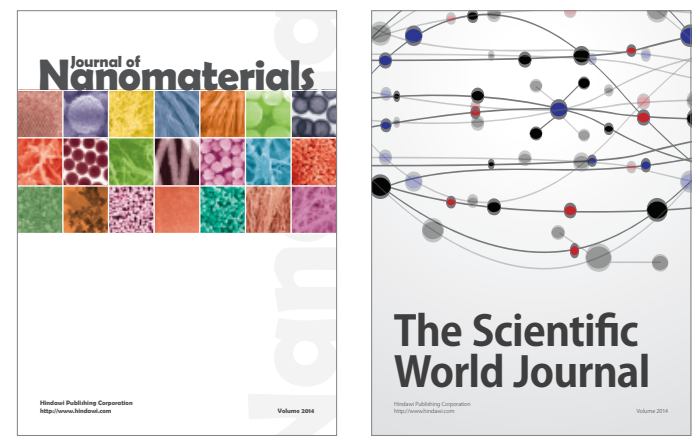

The Scientific World Journal
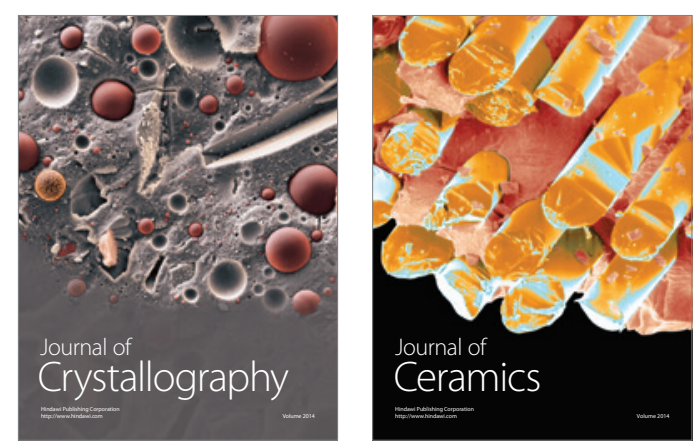
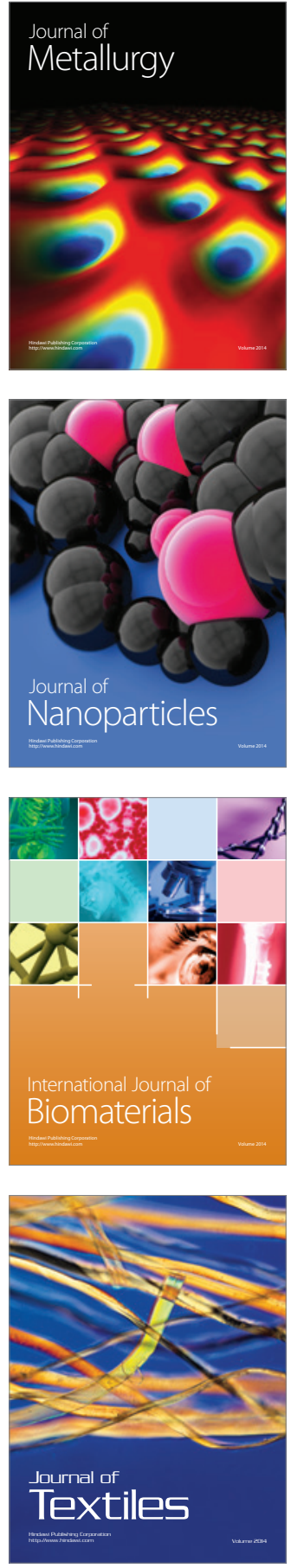